\title{
Ecobiological study of Artemia salina L. and first determination of the toxicity of ammonium sulphate
}

\author{
Mohammed Missoum Benmeddah, Mohamed Ali Bouzidi, Fawzia Toumi-Benali, Youcef Amar, \\ Sofiane Bouazza, Abbes Dellal, Mustapha Mahmoud Dif
}

Laboratory of Spaces Ecodevelopment, Faculty of Nature and Life Sciences, Djilali Liabes University of Sidi Bel Abbes, Sidi Bel Abbes 22000, Algeria, e-mail: medalibouzidi@yahoo.fr $\left({ }^{*}\right.$ corresponding author)

\begin{abstract}
The objective of this work is firstly an ecobiological study, which aims to determine whether salinity is favorable for a good reproduction rate of cysts in the Artemia salina L., a species known for its use in aquaculture. Secondly, a short-term test of ammonium sulfate toxicity on its vitality is carried out as its environment is permanently subjected to sulphate-laden waste. The work consists of subjecting the species to different salinities in order to produce a good yield in cysts, which once recovered, hatching and breeding is maintained until individuals reach the adult stage. A toxicological study using toxicity test (CL50) is then conducted to study the resistance of these adults with various concentrations of ammonium sulphate. The results obtained from the ecobiological study show a mean similar to the natural environment $(\mathrm{p}>0.05)$ with a favorable concentration for the reproduction of the species at a salinity of about $75 \mathrm{~g} \mathrm{dm}^{-3}$. The toxicity test indicates a CL50 equal to $75 \mathrm{mg} \mathrm{dm}^{-3}$ after 24 hours. It is obvious that Artemia salina L. can be cultivated by controlling its reproduction by varying the salinity rate for its use during different seasons of the year, thus ammonium sulphate from waste is considered as a limiting factor.
\end{abstract}

Key words: Artemia salina L., salinities, reproduction, toxicity, ammonium sulphate

\section{Introduction}

Ecological factors, such as salinity and temperature, play a very important role in the development of zoo planktonic species (Hoffmeyer 1994; Calbet et al. 2001; Vieira and Bio 2011; Lei et al. 2009; Bennabi et al. 2015). Thus, these crustaceans are characterized by a variation of their organic fluids in ionic compounds, that is, it is interesting to study their interactions with their environment (Parekh and Tank 2015).

Indeed, these species along with fish, being inhabitants of limnic ecosystems, cannot escape from the effects of industrial pollution and they are widely used to assess the health of ecosystems (Parekh and Tank 2015).

The salines of Bethioua (western Algeria) constitute a favorable environment for the development of crustacean species, of which Artemia salina L. remains the characteristic species of this environment. Unfortunately, this habitat is subjected to continued deterioration after various releases concentrated in sulphate generated by a salt factory built to improve the economic sector in the region (Bennabi et al. 2015).

Artemia salina L. easily adapts to changes in salinity and $\mathrm{pH}$ and to laboratory conditions, which justifies the selection of this species for acute toxicity testing to evaluate the impact of the factory on its survival in its natural environment (Kherraz-Chemlal et al. 2017).

Static toxicity tests provide faster and more repeatable dose-response curves for estimating the toxic effects of chemicals on aquatic organisms. Typically, acute toxicity tests are used to estimate the exposure concentration resulting in 50\% mortality (LC5O) of the organisms tested during a specified exposure period (Parekh and Tank 2015).

In this context, the objective of our work is to study the toxicity of ammonium sulphate on its survival in order to determine tolerable thresholds for its viability.

\section{Material and Methods}

\section{Biological material}

Artemia salina L. is a crustacean widely distributed in saline and hyper saline lakes around the world. Due to its privileged position in the food chain of fish larvae and shrimp post-larvae, this biological material has attracted the attention of scientists and has been the subject of extensive research. It is able to survive in saline environments (hyper-halines) in salt lakes, lagoons and salt marshes locally called "Sebkha". This species occupies biotopes with a tropical, subtropical or temperate 

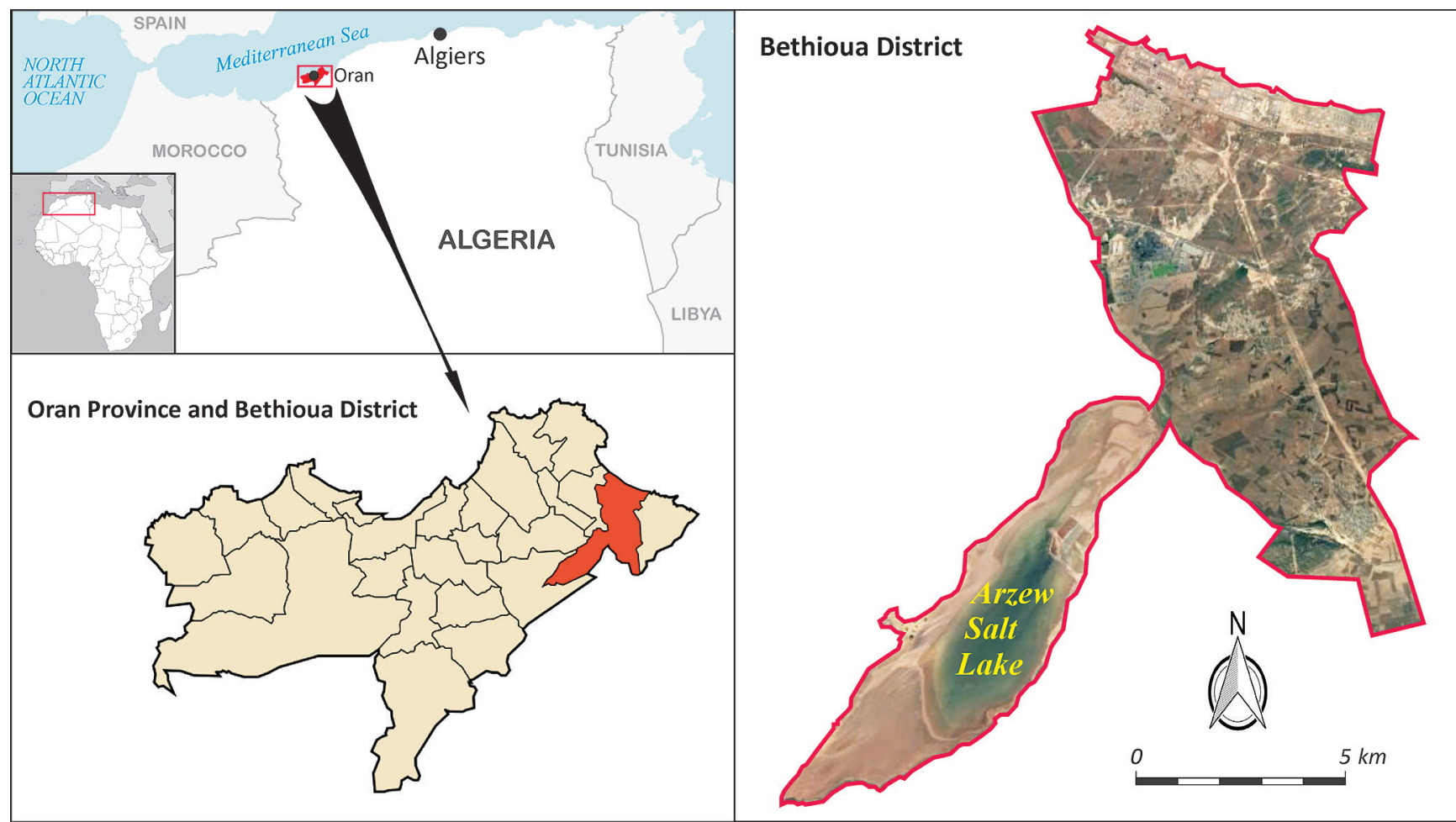

Fig. 1. Location of the collection area of Artemia salina L. species

climate (Lavens and Sorgeloos 2000). When the living conditions of the environment are no longer favorable after hydration to give birth to a larva called nauplius, in natural conditions Artemia salina L. is able to produce cysts, which are able to feed on algae, protozoa and detritus (Abatzopoulos et al. 2002).

\section{Sampling}

The species was collected from the Bethioua salt mines with geographical coordinates $0^{\circ} 17^{\prime} 50.92^{\prime \prime} \mathrm{W}$ and $35^{\circ} 41^{\prime} 38.70^{\prime \prime} \mathrm{N}$. They are part of the Oran Province, Bethioua District and the municipality of Boufatis. This salt is located in the south of a depression called "Arzew Salt Lake" (Fig. 1) with an area of 2700 hectares and characterized by a Mediterranean climate. Winter rains fill the lake and dissolve the salt layer lining the ground. The lake is currently under the direction of the National Salt Company (NSC).

\section{Toxicity test}

To obtain healthy adult species for the performance of the toxicity test, in vitro breeding from the cysts was performed.

First, to obtain a maximum number of cysts, seven concentrations of crude $\mathrm{NaCl}(50,75,100,125,150$, $175,200 \mathrm{~g} \mathrm{dm}^{-3}$ ) ware prepared in beakers each containing 10 females. A control was performed in parallel with females placed in a beaker containing saline wa- ter. Egg recovery was carried out according to the technique described by Person-Le Ruyet (Person-Le Ruyet 1976; Trigui et al. 2016).

Once the cysts were recovered, hatching and rearing followed to obtain biological material for the toxicity test. The toxicity test was performed according to the OECD (1992) method. To do this, we performed a 72 hour acute toxicity test on Artemia salina L. specimens recovered from our farm. Six concentrations of ammonium sulphate were prepared $(50,75,100,125,150$ and $200 \mathrm{mg} \mathrm{dm}^{-3}$ ) to test the tolerance of this species and to determine the $\mathrm{LC}_{50}$ (OECD 1992).

\section{Statistical Analysis}

The collected data were expressed as mean values ( \pm standard deviation). The data analysis was carried out using IBM SPSS Statistics, version 23.0 (IBM Corp. 2015). A one-way analysis of variance was used, followed by a significant Dunett's posteriori test. The differences are considered significant if $\mathrm{p}<0.05$, highly significant if $\mathrm{p}<0.01$ or very highly significant if $\mathrm{p}<0.001$.

\section{Results and discussions}

\section{Cysts Production}

After being subjected to different concentrations, Artemia salina L. produced a maximum number of $(87 \pm 4)$ cysts at salinity equal to $75 \mathrm{~g} \mathrm{dm}^{-3}$ compared 


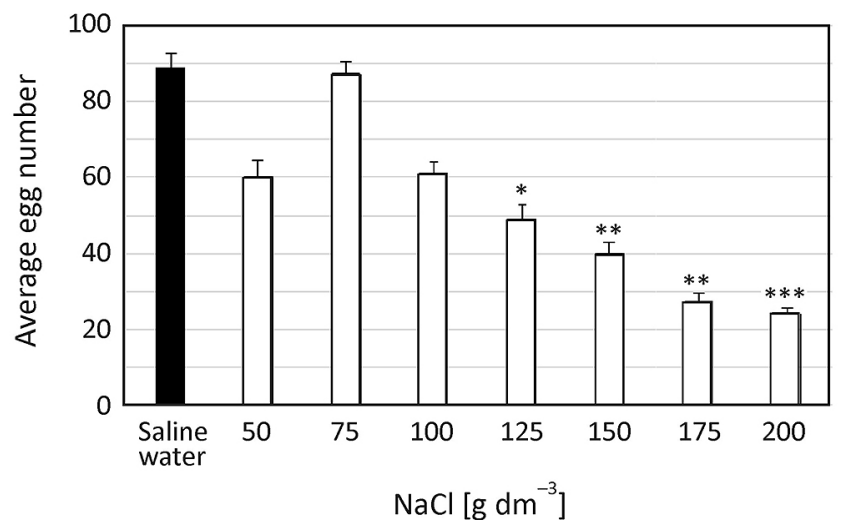

Fig. 2. Average egg numbers at different salinity conditions $(\mathrm{NaCl}$ concentration)

Explanation: significant differences $(\mathrm{p}<0.05)$ are marked with an asterisk, highly significant differences $(\mathrm{p}<0.01)$ with a double asterisk, and very highly significant differences $(\mathrm{p}<0.001)$ with a triple asterisk.

to other concentrations where the number of cysts was less important. This is equal to $(60 \pm 3),(61 \pm 3),(49 \pm 4)$,

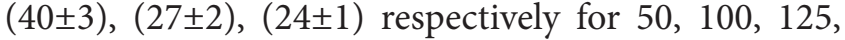
150, 175 and $200 \mathrm{~g} \mathrm{dm}^{-3}$ (Fig. 2). Thus, Artemia salina L. salines of Bethioua present their optimal production in cysts at salinity of the order of $75 \mathrm{~g} \mathrm{dm}^{-3}$.

The statistical analysis shows a non-significant difference in the number of cysts produced in the control (natural environment) and the concentrations $50 \mathrm{~g} \mathrm{dm}^{-3}(\mathrm{p}=$ $0.135), 75 \mathrm{~g} \mathrm{dm}^{-3}(\mathrm{p}=0.900)$ and $100 \mathrm{~g} \mathrm{dm}^{-3}(\mathrm{p}=0.149)$. On the other hand, this difference is highly significant with the highest concentrations, namely $125 \mathrm{~g} \mathrm{dm}^{-3}(\mathrm{p}=$ $0.022), 150 \mathrm{~g} \mathrm{dm}^{-3}(\mathrm{p}=0.004)$ and $175 \mathrm{~g} \mathrm{dm}^{-3}(\mathrm{p}=0.001)$, and strongly significant for the highest concentration of our experiment was $200 \mathrm{~g} \mathrm{dm}^{-3}(\mathrm{p}=0.000)$ (Fig. 2).

For species of the same genus, Browne et al. (2000) and Triantaphyllidis et al. (1995) found that the optimal salinity for cyst production of Tanggu's Artemia parthenogenetica ranged from 60 to $100 \mathrm{~g} \mathrm{dm}^{-3}$. while for the Artemia fransiscana L. species of San Francisco Bay the optimal salinity for the production of cysts was between 100 and $140 \mathrm{~g} \mathrm{dm}^{-3}$.

\section{Outbreak and rearing}

The cyst hatching was performed in an aquarium at a $\mathrm{NaCl}$ concentration equal to that of seawater $(36 \mathrm{~g}$ $\mathrm{dm}^{-3}$ ) at $25^{\circ} \mathrm{C}$. The hatching of the cysts is stimulated by the phenomenon of osmosis, which favors the bursting of the wall, and the birth of naupliis. They (240 individuals), are fed with rice flour and put in breeding at a concentration of $75 \mathrm{~g} \mathrm{dm}^{-3}$ until the adult stage (Sorgeloos et al. 2001).

\section{Toxicity test}

The 240 individuals of Artemia salina L. obtained were exposed to different concentrations of ammonium

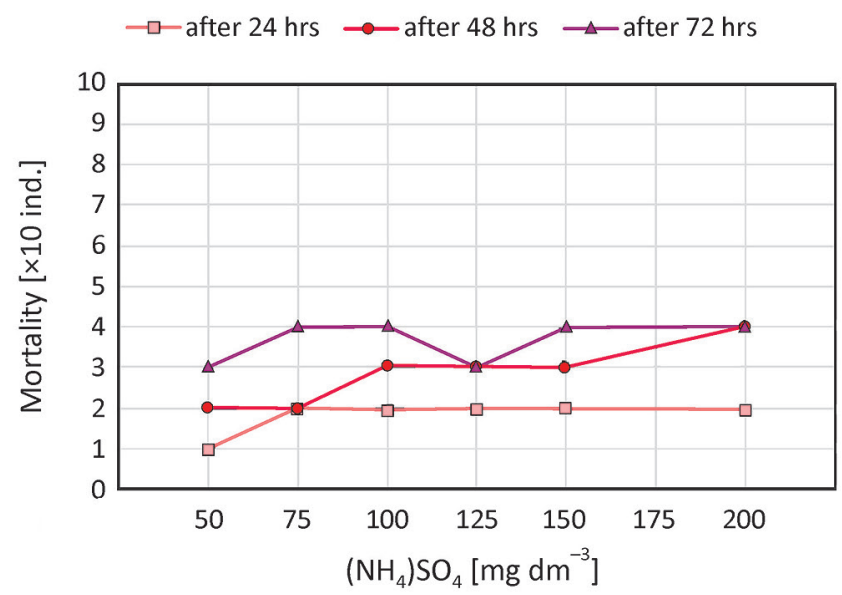

Fig. 3. Evolution of mortality according to the different concentrations of ammonium sulphate

sulphate at the rate of 40 individuals per concentration. Generally, the toxicity is expressed as a lethal concentration, which causes the death of $50 \%$ of the group of experiment species (LC50) (Libralato et al. 2016).

The results obtained indicate variability in the resistance of the species to the different concentrations of ammonium sulphate (Fig. 3). Its tolerance is observed at a concentration equal to $50 \mathrm{mg} \mathrm{dm}^{-3}$ where $25 \%$ of the individuals survived even after 72 hours of exposure. On the other hand, $50 \%$ of the individuals showed no resistance after 24 hours of exposure to the other concentrations.

After 48 hours, $75 \%$ of individuals died at concentrations of 100,125 , and $150 \mathrm{mg} \mathrm{dm}^{-3}$, while not all individuals resisted after this period at $200 \mathrm{mg} \mathrm{dm}^{-3}$.

After 72 hours of experimentation, there was total death of all individuals remaining in the other concentrations $\left(75,100,12\right.$, and $\left.150 \mathrm{mg} \mathrm{dm}^{-3}\right)$.

Our short-term toxicity test showed a $\mathrm{LC}_{50}$ equal to $75 \mathrm{mg} \mathrm{dm}^{-3}$ for the duration of 24 hours of exposure.

In other studies the effect of toxicity on Artemia salina L., Abu Shaala et al. (2015) have demonstrated a LC50 $=23.27 \mathrm{mg} \mathrm{dm}^{-3}$ for the toxicity of diuron on the morphology of the species. For the effect of copper sulphate, Manfra et al. (2015) found a LC50 $=23.31 \mathrm{mg}$ $\mathrm{dm}^{-3}$ and Libralato et al. (2016) performed toxicity tests for copper sulfate pentahydrate on the species with a LC50 $=6.6 \mathrm{mg} \mathrm{dm}^{-3}$ after 24 hours. However, our work is the first to highlight the toxicity of ammonium sulphate on Artemia salina L. in western Algeria.

The toxicity of each chemical differs from one organism to another (Patel et al. 2013). Delisle et al. (1977) and Greenwood et al. (1984), studied sulphates and found that high values of this parameter can be observed in polluted streams, at the level of industrial waste areas (mining industry, pulp and paper mills, tanneries, textile mills). It can also be found in agricultural 
activities involving the excessive use of insecticides and fungicides based on ammonium sulphate fertilizers (Derwich et al. 2010).

\section{Conclusion}

In the light of the present results, the reproductive dynamics in Artemia salina L. vary according to the ecological factors and the conditions of the environment in which it survives.

The species in question is a perfect food for marine life and good nutrition.

Although the optimum rate of salinity favoring reproduction is $75 \mathrm{~g} \mathrm{dm}^{-3}$, the most effective method of reproduction is not necessarily heterosexual reproduction. Indeed, under optimal conditions, parthenogenesis reproduction remains the most efficient from the point of view of the number of eggs hung.

Our study consists of examining the effect of certain pollutants, such as ammonium sulphate $\left(\mathrm{NH}_{4}\right)_{2} \mathrm{SO}_{4}$ on Artemia behavior.

As in most living things, adult individuals are the most resistant to attack from a polluted environment. But our study on the ammonium sulphate toxicity, where sulphate is the dominant element of the rejections generated by the salt plant on the species biotope, reveals that even at this stage the species cannot withstand a concentration over $75 \mathrm{mg} \mathrm{dm}^{-3}$.

Therefore, the conservation of this environment remains a primary necessity if one wants to develop a subsidiary of cyst production that constitutes a basic element in the aquaculture sector in order to improve the socio-economic framework of the neighboring populations.

Aquaculture has become one of the major sectors of food production to meet the needs of individuals and its development today ensures half of the production of fish consumed in the world. It should, however, be part of a sustainable and responsible process.

\section{References}

Abatzopoulos T.J., Beardmore J.A., Clegg JS.., Sorgeloos P. (eds), 2002, Artemia. Basic and applied biology, Kluwer Academic Publishers, Dordrecht, 286 pp.

Abu Shaala N., Zulkifli S., Ismail A., Azmai M., Yusuff M., 2015, Lethal concentration $50\left(\mathrm{LC}_{50}\right)$ and effects of Diuron on morphologyof brine shrimp Artemia salina (Branchiopoda: Anostraca) Nauplii, Procedia Environ. Sci. 30: 279-284.

Bennabi F., Benmeddah M., Toumi F., Hamel L., Megharbi A., Koudache F., Ghomari S., 2015, Etude éco-biologique d'Artémia salina des zones humides de l'Ouest Algérien (Eco-biological study of Artemia salina L. of West Alge- ria), Afrique Science 11(2): 97-106 (in French, English summary).

Browne R.A., Wanigasekera G., 2000, Combined effects of salinity and temperature on survival and reproduction of five species of Artemia, J. Exp. Mar. Bio. Ecol. 244: 29-44.

Calbet A., Garrido S., Saiz E., Alcaraz M., Duarte C.M., 2001, Annual zooplankton succession in coastal NW Mediterranean waters: the importance of the smaller fractions, J.Plankton Res. 23(3): 319-331.

Delisle C.E., Schmidt J.W., 1977, The effect of sulfur and water life in Canada, [in:] Cooke N.E. (ed.), Sulfur and its inorganic derivatives in the Canadian environment, Publ. No. NRCC 15015, Natn. Res. Coun. Can., Ottawa, 426 pp.

Derwich E., Benaabidate L., Zian A., Sadki O., Belghity D., 2010, Caracterisation physico-chimique des eaux de la nappe alluviale du haut Sebou en aval de sa confluence avec Oued Fès (Physico-chemical characterization of the waters of the Upper Sebou alluvial aquifer downstream from its confluence with Oued Fès), Larhyss J. 8: 101-112 (in French).

Greenwood N.N., Earnshaw A., 1984, Chemistry of the Elements, Pergamon Press, Oxford, 1542 pp.

Hoffmeyer M.S., 1994, Seasonal succession of Copepoda in the Bah í a Blanca estuary, Hydrobiologia 292(1): $303-$ 308.

IBM Corp., Released 2015, IBM SPSS Statistics for Windows (Version 23.0) [Computer software], IBM Corp., Armonk.

Kherraz-Chemlal D., Boukhatem T., Khelil F., Sahnouni F., Maatalah A., Boutiba Z., 2017, Determination of biological characteristics of Artemia salina (Crustacea: Anostraca) population from saline Bethioua (Oran, Algeria), Int. J. Biosci. 10(1): 117-125.

Lavens P., Sorgeloos P., 2000, The history, present status and prospect of the availability of Artemia cysts for aquaculture, Aquaculture 181: 397-403.

Lei Y., Xu K., Ki Choi J., Pyo Hong H., Wickham S.A., 2009, The structure and seasonal dynamics of planktonic ciliates along salinity gradients, Eur. J. Protistol. 45: 305-319.

Libralato G., Prato E., Migliore L., Cicero A.M., Manfra A., 2016, .Review of toxicity testing and endpoints with Artemia spp., Ecol. Indic. 69: 35-49.

Manfra L., Tornambè A., Savorelli F., Rotini A., Canepa S., Mannozzi M., Cicero A.M., 2015a, Ecotoxicity of diethylene glycol and risk assessment for marine environment, J. Hazard. Mater. 284: 130-135.

Manfra L., Savorelli F., Di Lorenzo B., Libralato G., Comin S., Conti D., Floris B., Francese M., Gallo M., L., Gartner, I., Guida, M., Leoni, T., Marino, G., Martelli, F., Palazzi, D., Prato, E., Righini, P., Rossi E., VolpiGhirardini A., Migliore L., 2015b, Intercalibration of ecotoxicity testing protocols with Artemia franciscana, Ecol. Indic. 57: 41-47.

[OECD] Organization for Economic Cooperation and Development, 1992, OECD Guideline for testing of chemicals. Test No. 203: Fish, acute toxicity test, OECD Publishing, Paris, 9 pp. 
Parekh H.M, Tank S.K., 2015, Studies of haematological parameters of Oreochromis niloticus exposed to cadmium chloride $\left(\mathrm{CdCl}_{2}, 2 \mathrm{H}_{2} \mathrm{O}\right)$, Int. J. Environ. 4(2): 116-127.

Patel J.G., Nirmal Kumar J.I., Kumar R.N., Shamiyan R.K., 2013, Chronic toxicity of high molecular weight polynuclear aromatic hydrocarbonpyrene on freshwater cyanobacterium anabaena fertlissimarao, Int. J. Environ. 2(1): $175-183$.

Person-Le Ruyet J., 1976, Techniques délevage en masse d'un rotifère (Brachionus plicatilis Müller) et d'un crustacé branchiopode (Artemia salina L) (Techniques of mass culture of the rotifer (Brachionus plicatilis Müller) and a branchiopod crustacean (Artemia salina L.), [in:] Persoone G., Jaspers E. (eds) Proc. of the10th European Symposium on Marine Biology. Vol. 1: Research in mariculture at laboratory- and pilot scale, 17-23 September 1975, Ostend: 331-343 (in French, English summary).
Sorgeloos P., Dhert P., Candreva P., 2001, Use of the brine shrimp Artemia spp. in marine larviculture, Aquaculture 200(1-2): 147-159.

Triantaphyllidis G.V., Poulopoulou K., Abatzpoulos T.J., Perez C.A., Sorgeloos P., 1995, International study on Artemia XLIX. Salinity effects on survival maturity, growth biometrics, reproductive and lifespan characteristics of a bisexual and parthenogenetic population of Artemia, Hydrobiology 302: 215-227.

Trigui K., Bensaid R., Akrout F., Aloui N., 2016, Etude écobiologique d'Artemia salina (Branchiopoda, Anostraca) de la saline de Sahline (Tunisie) (Eco-biological study of Artemia salina L. Branchiopoda, Anostraca in Sahline Salt Lake (Tunisia), Crustaceana 89(8): 949-974.

Vieira N., Bio A., 2011, Spatial and temporal variability of water quality and zooplankton in an artisanal salina, J. Sea Res. 65(2): 293-303. 